\title{
Sexual dimorphism and allometry of external morphology in 0 reochromis mossambicus
}

\author{
R. F. Oliveira and V. C. A lmada \\ U nidade de Investigação em E co-E tologia, Instituto Superior de P sicologia A plicada, \\ Rua J ardim do Tabaco 44, 1100 L isboa, P ortugal
}

(Received 9 A pril 1994, Accepted 14 August 1994)

\begin{abstract}
Sexual dimorphism in growth of conventional morphometric characters was investigated in juveniles and young adults (size range: 31 to $91 \mathrm{~mm}$ ) of Oreochromis mossambicus. A closely associated set of traits was identified that shows sexually dimorphic growth, which was positively allometric in the males. These traits correspond to two different morphological complexes: jaw structure and anal/dorsal fins. The best sex discriminators among this set of traits were premaxilla width, anal fin height and snout length. These findings may be explained in terms of intra- and inter-sexual selection acting together and favouring males with strong and large mouths and high dorsal and anal fins, traits that are important in agonistic displays (jaw and fins), fighting and nest digging (jaw).
\end{abstract}

K ey words: sexual dimorphism; growth allometry; cichlid biology; sexual selection.

\section{INTRODUCTION}

There has been considerable interest in the sexual dimorphism of tilapiine cichlids. Since in this group there are basic differences in the reproductive behaviour (biparental substrate brooders-Tilapia; paternal and biparental mouthbrooders-Sarotherodon; and maternal mouthbrooders-Oreochromis), some authors have attempted to relate the degree of sexual dimorphism with the mode of reproduction. In reviewing the literature on this topic, Trewavas (1983) noticed that ' in Tilapia there is no or minimal sexual dimorphism or dichromatism (...). Sarotherodon resembles Tilapia in this respect, but in Oreochromis males have distinctive and conspicuous breeding colours, are generally bigger than females and in some species have enlarged jaws and unicuspid teeth when mature; other males have a tassel-like appendage on the genital papilla'.

Other characteristics for which sexual dimorphism has been noted include dorsal and anal fins pointed in mature males and rounded in females [Sarotherodon galilaeus (L innaeus) and Oreochromis aureus (Steindachner), Chervinski, 1965], pelvic fins reaching or passing the anus in males but not in females [T ilapia zillii (G ervais), S. galilaeus and 0. aureus, Chervinski, 1983], males with one urogenital opening and females with two [T. zillii, S. galilaeus and 0 . aureus, Chervinski, 1983; 0. mossambicus (Peters), Datta \& Roy, 1984], a thicker and continuous dorsal fin in mature males and notched dorsal fin in females (0. aureus, Fishelson, 1966), and a thicker lip in upper jaw in mature males (0. mossambicus, Seitz, 1949).

Since males grow faster and reach larger sizes than females in most tilapiine species, it is important to determine to what extent these dimorphic characters 1055 
reflect true dimorphisms or are the result of simple allometric growth of the traits. This question becomes especially relevant when considering the fact that maturation may be reached at various sizes and is sensitive to several environmental factors (J ames \& Bruton, 1992). Brzeski \& D oyle (1988) working with a hybrid stock of 0 . mossambicus $\times 0$. urolepis hornorum (Trewavas) (D alhousie stock) found that, after correcting for size, the upper lip width and body depth measured at eye level and at the insertion of the dorsal fin were effective sex discriminators.

The present study examines the allometric growth patterns of a number of morphometric characters including those commonly used to distinguish sexes, and assesses their effectiveness in discriminating between males and females in 0 . mossambicus.

\section{MATERIALS AND METHODS}

FISH

The specimens examined came from a stock kept in our laboratory which is derived from the $V$ asco da Gama A quarium stock, that originated from individuals collected at Incomati River (M ozambique) in the early 1970s. Fish age ranged from 8 to 14 months and their standard length (S.L.) from 31-91 mm, with sexual maturation at minimum sizes at 67 and $61 \mathrm{~mm}$ for males and females, respectively.

They had two distinct origins: (1) stock aquaria groups of about 40 individuals per tank (130 I) ( $n=48)$; (2) small groups (used in behavioural studies) of six individuals per tank $(60 \mathrm{l})(\mathrm{n}=76)$.

$\mathrm{F}$ ish were fed commercial fish flakes, and were kept at $24 \pm 2^{\circ} \mathrm{C}$ with a photoperiod of 12L : 12D.

\section{PR OCEDURES}

Fish were killed with an overdose of quinaldine, measured with a calliper to the nearest $0.1 \mathrm{~mm}$ (Table I), and dissected for gonad examination. To sex immature fishes we used the aceto-carmine coloration method proposed by Guerrero \& Shelton (1974).

\section{DATA ANALYSIS}

A fter log transformation, each measure was regressed over the log standard length for fishes of each sex separately. The regression equations were compared using A nalysis of Covariance (A N COVA) and when neither slopes nor intercepts differed significantly $(\alpha=0.05)$ between the sexes, data for all fish were used to calculate a single regression equation. One-tailed confidence intervals for the slope were computed to test significant departures from isometry at three significance levels $(a=0.05, a=0.01, a=0.001)$. If the lower limit of the confidence interval for a given slope was greater than one the relationship was classified as positively allometric. Conversely, if the upper limit of a confidence interval was smaller than one it was classified as negatively allometric. In order to detect overall patterns of covariation between the different measures a Principal Component A nalysis (PCA) was performed, while the effectiveness of each measure to distinguish the sexes was determined by Discriminant A nalysis. In both PCA and in $D$ iscriminant A nalysis, residuals of the log-log regressions of each measure over standard length were used in order to correct for size effects. To test the reliability of subjective sex identification based on some characters referred to in the literature as sexually dimorphic (Chervinski, 1983) the K appa coefficient of concordance for nominally scaled data was used (Siegel \& Castellan, 1988). The $M$ ann-Whitney $U$-test was used for direct comparisons of individual measures between males and females. One-way A N OVA was used to compare PCA factor scores between males and females. 
TABLE I. M orphometric measurements used in the present study

\begin{tabular}{|c|c|c|}
\hline A bbreviations & Term & M ethod of measurement \\
\hline T.L. & Total length & $\begin{array}{l}\text { A nterior edge of the upper lip to the tip of } \\
\text { middle rays of caudal fin }\end{array}$ \\
\hline S.L. & Standard length & $\begin{array}{l}\text { A nterior edge of the upper lip to the base } \\
\text { of the caudal fin }\end{array}$ \\
\hline $\mathrm{HH}$ & Head height & $\begin{array}{l}\text { M aximum height between the dorsal and } \\
\text { ventral contour of the head }\end{array}$ \\
\hline $\mathrm{BH}$ & Body height & $\begin{array}{l}\text { M aximum height between the dorsal and } \\
\text { ventral contour of the body }\end{array}$ \\
\hline PDL & Pre-dorsal length & $\begin{array}{l}\text { A nterior edge of the upper lip to the } \\
\text { anterior insertion of the first dorsal fin }\end{array}$ \\
\hline PAL & Pre-anal length & $\begin{array}{l}\text { A nterior edge of the upper lip to the } \\
\text { anterior insertion of the first anal fin }\end{array}$ \\
\hline PPL & Pre-pelvic length & $\begin{array}{l}\text { A nterior edge of the upper lip to the base } \\
\text { of the pelvic fins }\end{array}$ \\
\hline PFL & Pelvis fin length & $\begin{array}{l}\text { Base of the left pelvic fin to the tip of its } \\
\text { largest ray. }\end{array}$ \\
\hline $\mathrm{CPH}$ & Caudal peduncle height & $\begin{array}{l}\text { M aximum height between the dorsal and } \\
\text { ventral contour of the caudal peduncle }\end{array}$ \\
\hline DFH & Dorsal fin height & $\begin{array}{l}\text { L ength of the largest fin ray of the second } \\
\text { dorsal fin }\end{array}$ \\
\hline AFH & A nal fin height & $\begin{array}{l}\text { L ength of the largest fin ray of the second } \\
\text { anal fin }\end{array}$ \\
\hline ED & Eye diameter & Horizontal diameter of the iris \\
\hline IOW & Inter orbital width & L east width of the skull between the eyes \\
\hline PW & Premaxilla width & M aximum width of the upper lip \\
\hline M W & $M$ andible width & $M$ aximum width of the lower lip \\
\hline PL & Premaxilla length & $\begin{array}{l}\text { A nterior edge of the upper lip to the } \\
\text { posterior edge of the jaw }\end{array}$ \\
\hline$H L$ & H ead length & $\begin{array}{l}\text { A nterior edge of the upper lip to the most } \\
\text { posterior part of the bony opercular edge }\end{array}$ \\
\hline SN L & Snout length & $\begin{array}{l}\text { A nterior edge of the upper lip to the } \\
\text { anterior edge of the orbit }\end{array}$ \\
\hline
\end{tabular}

\section{RESULTS}

M ORPHOLOGICAL CHARACTERS WITH SEXUALLY DIMORPHIC GROWTH

As is common in Tilapia, in our sample males were larger than females ( $M$ ann-W hitney $U$-test, $n=124:$ S.L.: $z=-3.75, \quad P \ll 0.001$; weight: $z=3.34$, $P \ll 0.001)$. This difference in size stresses the importance of analysing the relationship of each morphometric variable with size before any further interpretation of their contribution to sexual dimorphism. Inspection of Table II reveals that there is a set of measures whose variation with size differs significantly between the sexes (both in slope and intercept). A dditionally, PD L differs significantly in intercept but not in slope. The variables that yield significant results are related to two different morphological complexes namely jaw structure (PW, M W , PL, SNL) and anal/dorsal fins (AFH, DFH).

F or both morphological complexes, males show positive significant allometries with respect to size, while females show isometric relationships, except for the 
TABLE II. Comparison between male and female log-log regression equations of each morphometric variable over s.L. using A N COVA

\begin{tabular}{|c|c|c|c|c|c|}
\hline \multirow{2}{*}{ Variables } & \multirow{2}{*}{$\mathrm{n}$} & \multicolumn{2}{|c|}{$\begin{array}{l}\text { Differences among adjusted } \\
\text { means (intercept) }\end{array}$} & \multicolumn{2}{|c|}{$\begin{array}{l}\text { Differences among } \\
\text { slopes }\end{array}$} \\
\hline & & $F$ & P-level & $\mathrm{F}$ & P-level \\
\hline T.L. & 124 & 0.252 & NS & $1 \cdot 340$ & NS \\
\hline $\mathrm{HH}$ & 124 & 1.194 & NS & 0.349 & NS \\
\hline $\mathrm{BH}$ & 124 & 1.804 & NS & 1.202 & NS \\
\hline PDL & 124 & 4.240 & $<0.05$ & 0.280 & NS \\
\hline PAL & 124 & 0.321 & NS & 0.637 & NS \\
\hline PPL & 124 & 0.409 & NS & 3.849 & NS \\
\hline$P F L$ & 124 & $2 \cdot 351$ & NS & 0.007 & NS \\
\hline $\mathrm{CPH}$ & 124 & 0.004 & NS & 0.343 & NS \\
\hline DFH & 122 & 34.456 & $<0.001$ & 25.800 & $<0.001$ \\
\hline AFH & 124 & $27 \cdot 074$ & $<0.001$ & $5 \cdot 246$ & $<0.05$ \\
\hline ED & 124 & 2.724 & NS & 0.503 & NS \\
\hline $10 \mathrm{~W}$ & 124 & 0.989 & NS & 0.691 & NS \\
\hline PW & 124 & 41.457 & $<0.001$ & $15 \cdot 606$ & $<0.001$ \\
\hline M W & 124 & 5.751 & $<0.05$ & $18 \cdot 176$ & $<0.001$ \\
\hline$P L$ & 124 & $14 \cdot 440$ & $<0.001$ & 7.994 & $<0.01$ \\
\hline$H L$ & 118 & 1.742 & NS & 0.222 & NS \\
\hline SN L & 118 & $14 \cdot 512$ & $<0.001$ & 7.963 & $<0.01$ \\
\hline
\end{tabular}

A F H where females also show a small positive allometry (Table III). Concerning PDL, both sexes show a significant negative allometry with size (Table III). Of those variables whose relationship with size does not differ between the sexes, ED and PPL are negatively allometric while PFL shows a positive allometry (Table IV).

PCA of the correlation matrix among the residuals of all log-transformed variables regressed over log S.L. extracted two factors that explained $40.7 \%$ of the variance (T able $\mathrm{V})$. A lthough this value appears low for standard PCA results, it is not surprising due to the large number of variables that were previously shown not to differ between the sexes and must represent additional sources of variance in the population. U sing a cut-off value of 0.6 for the factor loadings, factor 1 expresses characters whose growth was revealed to be sexually dimorphic (DFH, AFH, PW, MW, PL), while factor 2 expresses variables associated with body height $(\mathrm{HH}, \mathrm{BH})(\mathrm{Fig} .1)$. In order to confirm that factor 1 represents characters with sexually dimorphic growth, factor scores were calculated for each individual and the values for males and females were compared separately for each factor. Factor 1 succeeded in discriminating among sexes (one-way A N OV A, $n=116, F=46.29, P<0.001)$, while the difference in factor 2 was not significant (one-way A N OVA, $n=116, F=2.41, P>0.05$ ).

\section{SEXUAL DIMORPHISM IN EXTERNAL MORPHOLOGY}

The analysis presented above allowed the identification of a single factor that expresses the characters that present sexually dimorphic growth. Since males may mature at different sizes and may vary in their expression of secondary sex 
T ABLE III. R egression equations of each log-transformed morphometric variable over log S.L. $\left(Y=a X^{b}\right)$, for characters that revealed differences between the sexes (either in slopes or in intercepts)

\begin{tabular}{|c|c|c|c|c|c|}
\hline Variables & $a$ & $b$ & $r$ & $F$ & Lc \\
\hline \multicolumn{6}{|l|}{ M ales: } \\
\hline DFH & -1.81 & 1.63 & 0.96 & $614 \cdot 9 * * *$ & $1 \cdot 40 * * *$ \\
\hline $\mathrm{AFH}$ & -1.41 & 1.40 & 0.97 & $978.5^{* * *}$ & $1 \cdot 24 * * *$ \\
\hline PW & -2.83 & 1.74 & 0.95 & $528 \cdot 0 * * *$ & $1 \cdot 48 * * *$ \\
\hline$M W$ & $-3 \cdot 33$ & 1.89 & 0.93 & $419 \cdot 1 * * *$ & $1 \cdot 57 * * *$ \\
\hline PL & -1.68 & $1 \cdot 41$ & 0.95 & $506 \cdot 2 * * *$ & $1 \cdot 20 * * *$ \\
\hline SN L & $-1 \cdot 28$ & 1.22 & 0.95 & $516 \cdot 7 * * *$ & $1 \cdot 36 * *$ \\
\hline PDL & -0.19 & 0.89 & 0.97 & $1142 * * *$ & $0.99 * * *$ \\
\hline \multicolumn{6}{|l|}{ F emales: } \\
\hline DFH & -0.97 & $1 \cdot 12$ & 0.90 & $249 \cdot 5 * * *$ & 0.98 \\
\hline $\mathrm{AFH}$ & $-1 \cdot 13$ & 1.22 & 0.92 & $335 \cdot 6 * * *$ & $1 \cdot 08 *$ \\
\hline $\mathrm{PW}$ & -1.94 & $1 \cdot 18$ & 0.78 & $92 \cdot 2 * * *$ & 0.94 \\
\hline M W & -1.80 & 0.99 & 0.53 & $23 \cdot 0 * * *$ & 0.58 \\
\hline PL & $-1 \cdot 16$ & 1.09 & 0.83 & $128 \cdot 5 * * *$ & 0.90 \\
\hline SN L & -0.86 & 0.96 & 0.87 & $165 \cdot 6 * * *$ & 0.81 \\
\hline PDL & -0.16 & 0.88 & 0.96 & $697 \cdot 7 * * *$ & $0.99 * * *$ \\
\hline
\end{tabular}

The correlation coefficient $(r)$, the value of the $F$ statistic ( $F$ ) and the critical limit for the confidence intervals (upper limit in the case of negative allometries, and lower limit in the case of positive allometries) $(\mathrm{L} c)$ are also presented. Three levels are used to express the significance yielded by each result: $* P<0.05$; $* * \mathrm{P}<0.01 ; * * * \mathrm{P}<0.001$. Sample size was 63 males and 61 females, except for DFH $(62$ males and 60 females) and SN L (61 males and 57 females).

T ABLE IV . R egression equations of each log-transformed morphometric variable over log S.L. $\left(Y=a X^{b}\right)$, for characters that did not reveal differences between the sexes (neither in slopes nor in intercepts)

\begin{tabular}{lccccc}
\hline Variables & $\mathrm{a}$ & $\mathrm{b}$ & $\mathrm{r}$ & $\mathrm{F}$ & $\mathrm{Lc}$ \\
\hline TL & -0.11 & 1.00 & 0.99 & $6949 * * *$ & 0.96 \\
H & -0.47 & 0.98 & 0.95 & $1191 * * *$ & 1.04 \\
BH & -0.40 & 0.99 & 0.94 & $990 \cdot 1 * * *$ & 1.05 \\
PAL & -0.12 & 0.98 & 0.98 & $3747 * * *$ & 1.01 \\
PPL & -0.23 & 0.91 & 0.96 & $1570 * * *$ & $0.98 * * *$ \\
PFL & -0.90 & 1.18 & 0.95 & $1196 * * *$ & $1.07 * * *$ \\
CPH & -0.84 & 0.99 & 0.97 & $1785 * * *$ & 1.04 \\
ED & -0.41 & 0.67 & 0.84 & $299.0 * * *$ & $0.79 * * *$ \\
IOW & -0.90 & 0.98 & 0.95 & $1047 * * *$ & 1.04 \\
HL & -0.53 & 1.05 & 0.90 & $492.5 * * *$ & 0.95 \\
\hline
\end{tabular}

The correlation coefficient $(r)$, the value of the $F$ statistic $(F)$ and the critical limit for the confidence intervals (upper limit in the case of negative allometries, and lower limit in the case of positive allometries) $(\mathrm{L} c)$ are also presented. Three levels are used to express the significance yielded by each result: $* \mathrm{P}<0.05$; $* * \mathrm{P}<0.01 ; * * * \mathrm{P}<0.001$. Sample size was 63 males and 61 females, except for $\mathrm{HL}$ ( 61 males and 57 females).

characters, a discriminant analysis was performed to evaluate the way in which the different measures are effective in distinguishing between the sexes (Table VI). Discriminant analysis correctly classified $81 \%$ of the cases (Wilk's $\lambda=0.614$, 
TABLE V. Principal components analysis results

\begin{tabular}{lcccc}
\hline Factor & Eigenvalue & $\begin{array}{c}\% \text { Total } \\
\text { variance }\end{array}$ & $\begin{array}{c}\text { Cumulative } \\
\text { eigenvalues }\end{array}$ & $\begin{array}{c}\text { Cumulative } \\
\%\end{array}$ \\
\hline 1 & 4.62 & 28.85 & 4.62 & 28.85 \\
2 & 1.90 & 11.89 & 6.52 & 40.74 \\
\hline
\end{tabular}

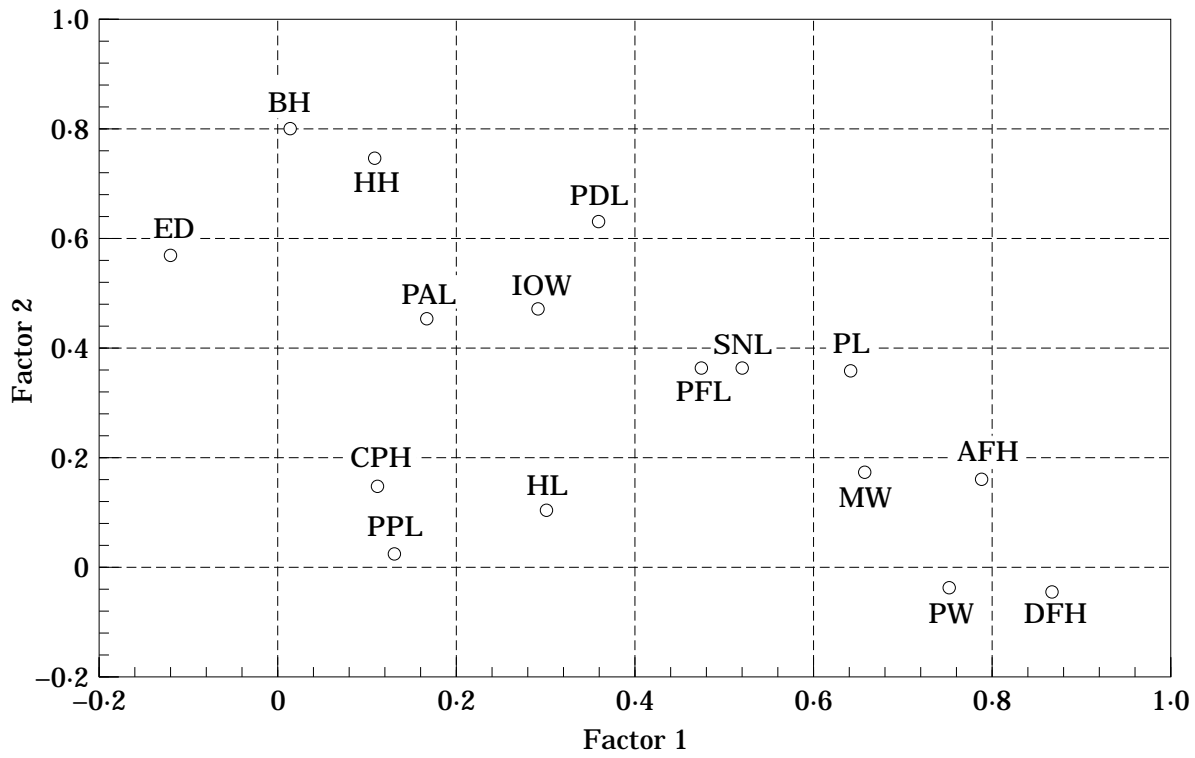

F IG. 1. Factor loadings for each morphometric variable on the two extracted PCA factors after varimax normalized rotation. A bbreviations are given in Table I.

$F(16,99)=3.89, P \ll 0.001)$. U sing $F$ values that yield significant results, a reduced discriminant function was obtained (score $=0.688 \mathrm{PW}+0.431 \mathrm{~A} \mathrm{~F} \mathrm{H}+0.209 \mathrm{SN} \mathrm{L}$ ) that adequately classified $77 \cdot 6 \%$ of the individuals (Wilk's $\lambda=0 \cdot 696$, $\mathrm{F}(3,112)=16 \cdot 32, \mathrm{P} \ll 0 \cdot 001)$. Thus, the traits that are most effective in discriminating the sexes belong to the group associated with PCA factor 1.

For practical purposes a number of characters have been used in visual identification of the sexes: (1) number of urogenital openings (females, 2; males, 1); (2) shape of the dorsal and anal fin (females, rounded; males, pointed), relative length of pelvic fins (females, not reaching the anus; males, reaching behind the anus). To determine the agreement in sex identification between each of these criteria and the sex determined by direct inspection of the gonads, we computed $\kappa$ statistics for the whole sample and for three size classes separately (T able VII). Considering the whole sample the criteria that best accomplish sex discrimination were anal/dorsal fin shape and the number of urogenital openings. The situation is different when each size class is considered separately. Pelvic fins were effective to sex 'small ' and 'medium ' fish but failed to do so in 'large' 
TABLE VI. D iscriminant analysis results

\begin{tabular}{lrrr}
\hline Variables & $\begin{array}{c}\text { Standardized } \\
\text { discriminant } \\
\text { function } \\
\text { coefficients }\end{array}$ & \multicolumn{2}{c}{$\begin{array}{c}\text { Classification functions } \\
\text { coefficients }\end{array}$} \\
\cline { 3 - 4 } & & M ales & F emales \\
\hline HH & 0.32 & -8.36 & 8.96 \\
BH & 0.16 & -3.85 & 4.12 \\
PDL & -0.21 & 7.87 & -8.44 \\
PAL & -0.06 & 2.71 & -2.90 \\
PPL & 0.10 & -3.26 & 3.49 \\
PFL & 0.30 & -6.61 & 7.09 \\
CPH & 0.03 & -1.00 & 1.08 \\
DFH & -0.18 & 2.66 & -2.85 \\
A FH & -0.55 & 11.12 & -11.91 \\
ED & 0.26 & -5.14 & 5.50 \\
IOW & 0.01 & -0.32 & 0.35 \\
PW & -0.49 & 5.34 & -5.72 \\
M W & 0.14 & -1.06 & 1.13 \\
PL & -0.03 & 0.40 & -0.43 \\
HL & 0.09 & -1.35 & 1.45 \\
SN & -0.41 & 7.03 & -7.53 \\
Constant & & -0.95 & -1.06 \\
\hline
\end{tabular}

fish. Both anal/dorsal fins and genital papilla were good predictors of the sex in 'medium' and 'large' individuals.

\section{DISCUSSION}

Brzeski \& Doyle (1988) in a study of sexual dimorphism of a hybrid of 0 . mossambicus $\times 0$. urolepis hornorum found, based on discriminant analysis, that the best criteria to sex the fish were premaxilla width, body length at eye level and at insertion of dorsal fin (A 2 and A 4 distances of the truss morphometrics). In contrast, we found that characters related to body height were not sexually dimorphic in their growth and were extracted in a non-sexually dimorphic factor by PCA. They were also not represented in the reduced model of the discrimination function. This apparent contradiction is easily explained if one considers that the height of dorsal and anal fins and snout length, which are not used in truss analysis and so were not used in Brzeski \& D oyle (1988) set of characters, are strongly dimorphic and two of them are among the three best sex discriminators. This is in agreement with results of $\kappa$ statistics that show that the shape of median fins was highly effective for sex identification in individuals larger than $50 \mathrm{~mm}$.

The identification of dimorphic traits that have differential allometric growth related to sex may be used in the future to assess the relative degree of secondary sex character differentiation of males that mature at different sizes and/or differ in their social status. In the present study a set of traits whose growth tends to accelerate in males was identified. These characters fall into two morphological 
TABLE VII. Concordance in sex identification between morphological characters and direct observation of the gonads ( $n=123$, except for the number of urinogenital openings where $n=44)$, for the whole sample and for size classes

\begin{tabular}{|c|c|c|c|c|}
\hline & $\kappa$ Statistics & $\begin{array}{l}\text { A nal/dorsal } \\
\text { fins }\end{array}$ & $\begin{array}{l}\text { Relative } \\
\text { pelvic } \\
\text { fin length }\end{array}$ & $\begin{array}{l}\mathrm{No} \text { o. of } \\
\text { urinogenital } \\
\text { openings }\end{array}$ \\
\hline W hole sample & $\begin{array}{c}\text { Observed concordance (\%) } \\
\kappa \\
Z \\
\text { P-level }\end{array}$ & $\begin{array}{l}79.7 \\
0.596 \\
6.65 \\
<0.001\end{array}$ & $\begin{array}{l}58.5 \\
0.161 \\
1.76 \\
<0.05\end{array}$ & $\begin{array}{l}79.6 \\
0.597 \\
5.72 \\
<0.001\end{array}$ \\
\hline $\begin{array}{l}\text { 'Small ' class } \\
\text { (31-51 mm S.L.) }\end{array}$ & $\begin{array}{c}\text { Observed concordance (\%) } \\
\kappa \\
\mathrm{Z}\end{array}$ & $\begin{array}{l}62.5 \\
0.04 \\
0.18\end{array}$ & $\begin{array}{l}53 \cdot 2 \\
0 \cdot 12 \\
2 \cdot 82\end{array}$ & $\begin{array}{l}77 \cdot 8 \\
0.40 \\
0.92\end{array}$ \\
\hline 'M edium ' class & $\begin{array}{c}\text { P-level } \\
\text { Observed concordance (\%) }\end{array}$ & $\begin{array}{c}\text { NS } \\
83 \cdot 1\end{array}$ & $\begin{array}{l}<0.01 \\
60.6\end{array}$ & $\begin{array}{l}\text { NS } \\
77 \cdot 3\end{array}$ \\
\hline (51-71 mm S.L.) & $\begin{array}{c}\kappa \\
Z \\
P \text {-level }\end{array}$ & $\begin{array}{r}0.66 \\
5.56 \\
<0.001\end{array}$ & $\begin{array}{r}0.22 \\
1.86 \\
<0.05\end{array}$ & $\begin{array}{r}0.55 \\
2.64 \\
<0.01\end{array}$ \\
\hline $\begin{array}{l}\text { 'L Large' class } \\
\text { (71-91 mm s.L.) }\end{array}$ & $\begin{array}{c}\text { Observed concordance (\%) } \\
\kappa \\
Z \\
\text { P-level }\end{array}$ & $\begin{array}{r}95.0 \\
0.86 \\
2.82 \\
<0.01\end{array}$ & $\begin{array}{l}60.0 \\
-0.25 \\
-0.77 \\
\quad \text { NS }\end{array}$ & $\begin{array}{r}92.3 \\
0.81 \\
2.36 \\
<0.01\end{array}$ \\
\hline
\end{tabular}

complexes: (1) jaw structure (PW, M W, PL, SN L) and (2) height of dorsal and anal fins $(D F H, A F H)$. These results are in accordance with the qualitative osteological description of the head of 0 . mossambicus performed by $C$ hardon $\&$ $\checkmark$ andewalle (1971), who showed that males have larger and more robust jaws than females, and with the common knowledge that males have pointed dorsal and anal fins.

Concerning the adaptive significance of this set of traits, we suggest that this pattern of dimorphic growth can be explained by the action of sexual selection. In 0 . mossambicus males do not mouthbrood and, as was found by Chardon \& $V$ andewalle (1971), although males have a larger and stronger mouth, females have a larger buccal cavity due to a larger development of the preopercular and interopercular bones. Thus, the greater development of the 'jaw structure complex ' must be related to specific features of male biology.

$D$ uring the breeding season, males of 0 . mossambicus concentrate in breeding arenas where they establish densely packed territories centred on a mouth-dug pit (Bruton \& Boltt, 1975). This pit is used to attract females to spawn, upon which the females take the eggs in their mouth, and leave the male territory. $M$ ales keep their territories inside the breeding arena by frequent agonistic interactions in which the mouth is used in two ways: (1) mouthfighting, a behaviour in which the opponents forcefully grip each other's mouths; and (2) frontal display, in which the wide open mouth is a prominent feature (Baerends \& Baerends van Roon, 1950). Additionally the mouth is used by territorial males in continually enlarging and reshaping the nest.

Studies in wild populations of other arena-breeding cichlids revealed a positive correlation between nest size and reproductive success (M cK aye et al., 1990). In 
captive 0 . mossambicus, we also found an association between dominance, nest size and access to females (personal observations).

Thus a strong and large mouth may be selected in two ways: (1) by intrasexual selection due to the role of the mouth in agonistic behaviour; (2) by intersexual selection, since a strong and wide mouth will enable a male to dig quickly a large nest. It could be argued that, since this species is an opportunistic feeder that occasionally feeds on small animals (Trewavas, 1983), a larger mouth could be favoured by selection since it would facilitate the capture of larger prey. This hypothesis does not explain however the differential enlargement of the mouth observed between the sexes. Indeed if the enlargement of the mouth had been selected for prey capture efficiency it would also be important for females which are subject to heavy nutritional demands for egg production. F urthermore, the available literature indicates that this species feeds predominantly on detritus and plankton (Bowen, 1982; T rewavas, 1983) and the morphology of the mouth, with pharyngeal bone plates, limits the efficiency of these fishes in handling large prey (Trewavas, 1983).

The ' anal/dorsal fins complex ' may also be subjected to intrasexual selection, as another important agonistic behaviour pattern in this species is lateral display, in which the males maximize the surface exhibited to the opponent through full erection of dorsal and anal fin (Baerends \& Baerends van R oon, 1950).

Thus, similar selective pressures stemming from intrasexual selection may act simultaneously on mouth and fin morphology, thus explaining the strong association of growth of these dimorphic traits. Intersexual selection may reinforce intrasexual selection of these traits, since it was previously demonstrated for other arena-breeding cichlids that females prefer to spawn with males whose nests are not only deeper but were centrally located in the arena (M CK aye, 1991; A. Rossiter, pers. comm.), which in turn implies the ability to dig effectively and defend the preferred sites.

The diversity of conditions under which 0 . mossambicus is found presently both in natural and artificial water bodies, with different growth patterns and breeding densities, provides a good comparative base to test the hypothesis presented above with natural populations.

The authors thank Laboratório M arítimo da Guia (U niversidade de Lisboa) where part of this study was conducted, and especially its director Professor L uis Saldanha; Pedro Ré and Emanuel Gonçalves for their assistance during the experiments; Peter Wirtz and two anonymous referees for valuable comments on the manuscript; and $\mathrm{H}$ unter $\mathrm{H}$ alder who reviewed the English. Rui Oliveira was supported by a PhD R esearch grant (J NICT BD/1032/90-IG).

\section{R eferences}

Baerends, G. P. \& Baerends van R oon, J. M . (1950). A n introduction to the study of the ethology of cichlid fishes. Behaviour, suppl. 1, 1-243.

Bowen, S. H. (1982). F eeding, digestion and growth-qualitative considerations. In The Biology and Culture of Tilapias (Pullin, R. S. V. \& L owe-M cConnell, R. H. eds), pp. 141-156. M anila: ICLARM .

Bruton, M . N . \& Boltt, R . E. (1975). A spects of the biology of Tilapia mossambica Peters (Pisces: Cichlidae) in a natural freshwater lake (Lake Sibaya, South A frica). J ournal of Fish Biology 7, 423-445. 
Brzeski, V. J \& \& oyle, R . W . (1988). A morphometric criterion for sex discrimination in Tilapia. In The Second International Symposium on Tilapia in A quaculture (Pullin, R. S. V., Bhukaswan, T., Tonguthai, K. \& M aclean, J. L., eds), pp. 439-444. $M$ anila: ICLAR M Conference Proceedings 15.

Chardon, M . \& Vandewalle, P. (1971). Comparaison de la région céphalique chez cinq espèces du genre Tilapia, donc trois incubateurs buccaux. A nnales de la Sociétè $R$ oyale de $Z$ oologie de Belgique 101, 3-24.

Chervinski, J. (1965). Sexual dimorphism in Tilapia. N ature 208, 703-704.

Chervinski, J. (1983). Sexual dimorphism in Tilapias. A quaculture 35, 171-172.

D atta, N . C. \& R oy, P. K . (1984). U rinogenital system of the exotic cichlid, Sarotherodon mossambica (Peters). International J ournal of the Academy of Ichthyology, M odinagar 5, 49-54.

F ishelson, L. (1966). Cichlidae of the genus Tilapia in Israel. Bamidgeh 18, 67-80.

Guerrero, R. D., III \& Shelton, W. L. (1974). An aceto-carmine squash method for sexing juvenile fishes. The Progressive Fish-C ulturist 36, 56.

James, N . P. E. \& Bruton, M . N . (1992). A Iternative life-history traits associated with reproduction in Oreochromis mossambicus (Pisces: $C$ ichlidae) in small water bodies of the eastern Cape, South A frica. Environmental Biology of Fishes 34, 379-392.

M cK aye, K. R. (1991). Sexual selection and the evolution of the cichlid fishes of Lake M alawi, Africa. In Cichlid Fishes-Behaviour, Ecology and Evolution (K eenleyside, M. H. A., ed.), pp. 241-257. London: Chapman \& H all.

M cK aye, K. R., L ouda, S. M. \& Stauffer, J. R., Jr (1990). Bower size and male reproductive success in cichlid fish lek. A merican Naturalist 135, 597-613.

Seitz, A. (1949). Vergleichende Verhaltensstudien an Buntbarschen (Cichlidae). Z eitschrift für T ierpsychologie 6, 202-235.

Siegel, S. \& Castellan, N. J., Jr (1988). Nonparametric Statistics for the Behavioral Sciences, 2nd edn. N ew Y ork: M cG raw-H ill.

Trewavas, E. (1983). Tilapiine Fishes of the Genera Sarotherodon, Oreochromis and D anakilia. L ondon: British M useum ( $\mathrm{N}$ atural $\mathrm{H}$ istory). 